\title{
A judicialização da política afirmativa como arena do conflito étnico-racial
}

\section{The judicialization of affirmative action as the arena of the ethnic-racial conflict}

\author{
Lucas Correia de Lima \\ Doutorando em Direito (UFBA) \\ Universidade Federal da Bahia (UFBA) \\ Cruz das Almas, Bahia, Brasil \\ E-mail: lucascorreia303@gmail.com
}

\author{
Rita De Cássia Dias Pereira Alves \\ Doutora em Educação (UFBA) \\ Universidade Federal da Bahia (UFBA) \\ Cruz das Almas, Bahia, Brasil \\ E-mail: rcdias@ufrb.edu.br
}

\begin{abstract}
Resumo: Recentemente, foi divulgada a formação da primeira turma de egressos negros do curso de medicina da Universidade Federal do Recôncavo da Bahia. Inobstante o fruto desta ação afirmativa universitária, nos bastidores da gestão, decisões judiciais têm sido proferidas contra as cotas, ameaçando a autonomia institucional e comprometendo que esta primeira turma torne-se a última decorrente do êxito desta política no Recôncavo baiano, região predominante negra e carente tanto de profissionais médicos quanto de representatividade neste segmento. O presente trabalho, portanto, tem por objeto o estudo do fenômeno da judicialização da política afirmativa étnicorracial aplicada no Bacharelado Interdisciplinar daquela universidade. Objetiva-se compreender os impactos deste fenômeno para a continuidade do projeto de gestão afirmativa com lastro na função social universitária de justiça racial. Propõe-se a investigação a partir da técnica metodológica de análise de conteúdo dos argumentos das peças processuais obtidas de processos judiciais nos casos de contestação da adoção das cotas. No contexto político de crise às universidades, traçam-se hipóteses para o fortalecimento da defesa universitária na manutenção de sua política contra o racismo institucional de um ativismo judicial às avessas.
\end{abstract}

Palavras-chave: Judicialização. Universidade. Política afirmativa. Medicina.

\begin{abstract}
The negative impacts resulting from disasters in cities have been one of the biggest issues faced by local managers Recently, the formation of the first class of black graduates of the medical course of the Federal University of Bahia's Recôncavo was announced. Despite the fruit of this affirmative university action, behind the scenes of management, judicial decisions have been issued against quotas, threatening institutional autonomy and compromising that this first class becomes the last one resulting from the success of this policy in the Bahia's Recôncavo, the predominant black region. lacking both medical professionals and representativeness in this segment. The present work, therefore, has as its object the study of the phenomenon of the judicialization of the ethno-racial affirmative politics applied in the Interdisciplinary Bachelor of that university. The objective is to understand the impacts of this phenomenon for the continuity of the affirmative management project based on the university social function of racial justice. It is proposed to investigate from the methodological technique of content analysis of the arguments of the procedural pieces obtained from court proceedings in cases of contestation of the adoption of quotas. In the political context of crisis to the universities, hypotheses are outlined for the strengthening of the university defense in the maintenance of its policy against the institutional racism of a reverse judicial activism.
\end{abstract}

Keywords Judicialization. University. Affirmative action. Medicine. 


\section{Introdução}

A política de cotas raciais no Brasil teve sua inauguração na esfera social tumultuada por contestações judiciais, muito embora a concepção da necessidade de formulação e execução de ações afirmativas, fundada na perspectiva de igualdade material, já estivesse sendo aplicada em outros âmbitos, a exemplo das políticas afirmativas para mulheres, no sistema político, e para as pessoas com deficiência, no mercado de trabalho.

Silva (2006) anota que nos anos que se seguiram à implementação das políticas de cotas raciais foram registradas trezentas ações judiciais "contra diversas universidades que as adotaram" (SILVA, 2006, p. 8). Tal fato nos revela que as batalhas judiciais foram travadas imediatamente após a inauguração dessas políticas, em evidente projeto para barrar o acesso da população negra ao ensino superior, contrastando-se com a aceitação social dessas mesmas ações para outras categorias de sujeitos, também tidos como sóciohistoricamente vulneráveis (SILVA, 2006).

Um dos maiores desafios na seara judicial da política de cotas se deu com o julgamento da Arguição de Preceito Fundamental (ADPF) n.ํ 186. Apesar da declaração de constitucionalidade, disputas judiciais não deixaram de surgir a pretexto de impugnar os fundamentos da ação afirmativa, esta, agora, sob as modernas roupagens aptas a contemplar novas demandas de democratização do acesso e permanência da comunidade negra na universidade.

A interferência de impugnações judiciais no desenvolvimento da política de cotas tem alterado a face da gestão universitária, resvalando na necessidade das universidades reafirmarem sua autonomia contra argumentos contestadores que, reiteradamente e sob novos fundamentos, ameaçam o aprimoramento das ações afirmativas.

Com o aprimoramento das políticas de cotas raciais, a população negra se vê mais próxima da realização do acesso ao ensino superior e, muitas vezes, da alteração de conjuntura de vida mediante uma reparação histórica. O negro, agora, está "mais próximo de ser doutor", como mostram os dados de Alves et al. (2017):

[...] os dados extraídos de uma análise sobre a gestão universitária da UFRB apontam os avanços na questão da igualdade racial. Dos 198 discentes matriculados regularmente no curso de graduação de medicina, 120 discentes se autodeclaram negros - considerando a categoria de negros a soma dos pretos e pardos, de acordo com a padronização do IBGE (ALVES et al., 2017, p. 11).

Contudo, quanto mais a população negra se desborda no avanço do ensino superior e do alcance da igualdade, com ingresso em áreas de poder historicamente elitistas, novos meios de impugnação surgem como obstáculos à evolução e efetivação dos direitos. Um dos pontos nevrálgicos deste acesso do sujeito negro a cursos de grande prestígio ocorre na graduação de Medicina.

O curso de Medicina é conhecido por ser um curso de "caráter elitista" (SANTOS, 2017, p. 44), reconhecido entre os próprios discentes como um "'lugar 'branco"' (idem, p. 42). Tal contexto racial excludente contrasta com o perfil oficial delineado das comunidades dos municípios do Recôncavo, cuja população é de maioria negra e de perfil financeiro pequeno (SEI, 2010). Desta forma, o curso de Medicina, historicamente, não é um curso destinado para acolhimento de estudantes negros. A repercussão dessa hostilidade 
educacional a um segmento racial resvala em outro dado consequente: médicos negros são menos de $18 \%$ do contingente de sua classe (OLIVEIRA, 2014).

A partir do momento que se verifica a importância de uma política de reserva de vagas que garanta o acesso racial de estudantes negros a um curso reconhecidamente branco em sua história educacional brasileira, e tenta-se implantar um projeto de reparação racial com o escopo de alterar essa realidade neste segmento profissional, que obstáculos de índole jurídica surgem quanto à aplicação de tais cotas.

\section{É neste ponto que se debruça o presente trabalho.}

Esta pesquisa, de natureza documental, foi realizada a partir dos arquivos eletrônicos da Justiça Federal, com foco sobre as sentenças proferidas na Seção Judiciária de Salvador, cidade onde se encontra a competência para julgamento de processos relativos à Universidade Federal do Recôncavo da Bahia (UFRB), conforme preconizado pela Resolução n. 08 de 2016 do Tribunal Regional Federal da 1르 Região.

A escolha da UFRB enquanto campo de pesquisa do fenômeno da judicialização se deu em razão de alguns aspectos considerados relevantes. O primeiro deles foi a representatividade negra do seu corpo discente e a magnitude dessa comunidade frente aos demais dados de outras instituições universitárias, revelando-se a maior comunidade negra de estudantes do país ao tempo desta pesquisa.

Um segundo ponto observado é a escassez de profissionais médicos na região do Recôncavo e o consequente impacto social que um curso superior de medicina ofertado pela Universidade proporciona para a alteração do contexto fático do espaço em que se insere.

Um último aspecto é a juventude do curso de Medicina e da própria Universidade; esta, criada por lei em 2005, conta com menos de duas décadas de existência. A recente inauguração da instituição permite buscar melhor o termo inicial do processo de judicialização no seu meio acadêmico e realizar uma análise pormenorizada dos processos judiciais em trâmite acerca da questão, sem os problemas de encontrar uma vastidão de outras impugnações, por motivos diversos, que uma Universidade secular poderia trazer para a pesquisa, demandando maior tempo, buscas e recursos para a concretização completa do estudo.

Do universo de 39 (trinta e nove) processos judiciais achados contra a UFRB sobre o tema das cotas, convencionou-se, em razão da proposta de tempo do trabalho, escolher quatro cadernos processuais para objeto de estudo, e destes, a pesquisa objetivou apenas a leitura analítica do ato jurídico final do processo - a sentença, cujo teor permite analisar toda uma retrospectiva do andamento do processo, dos argumentos levados para a causa por ambas as partes e, o que mais sobreleva para esta pesquisa, a interpretação legal sobre a política afirmativa pelo julgador enquanto intérprete e pretenso garantidor da ordem jurídica e dos direitos em discussão. A leitura da decisão final permitiu ainda extrair os elementos fundamentais que levaram à judicialização da demanda, assim como os fundamentos que embasaram seu desfecho.

Os referidos autos processuais são considerados, para todos os fins de pesquisa, como sendo arquivos públicos, os quais, na concepção de Chizzoti compõem-se dos "documentos recebidos ou produzidos por organismos públicos" (2005, p. 115). O emprego dos dados desses processos públicos oferece grandes vantagens a esta pesquisa, tanto em termos de economia de tempo, quanto sobre o caráter de coleta de tais 
dados sobre o evento natural e rotineiro da judicialização da política afirmativa de cotas. Economia, pois a coleta das informações já se encontra feita por órgãos públicos oficiais, não havendo que se buscá-la, senão nos próprios registros públicos. Doutro lado, considerando que o caderno processual representa a rotina da atividade jurisdicional, exercida de modo natural, torna-se possível ao pesquisador extrair das informações dos registros o que lhe for pertinente ao estudo, aferindo uma eventual tendência acerca do posicionamento políticocientífico dos sujeitos sobre o tema versado.

\section{A Universidade Federal do Recôncavo da Bahia e seu projeto de justiça racial}

Apesar de ser dito que a Universidade guarda estreita correspondência com a sociedade, inclusive no que tange aos problemas vividos por esta, quando se faz um recorte racial sobre a educação brasileira, evidencia-se que a instituição de ensino superior é muito "mais elitista do que a própria sociedade" (OLIVEIRA; BITTAR, 2010, p. 11).

Construída como espaço de prestígio por excelência, a universidade pública brasileira tem em sua raiz histórica o funil excludente da seletividade social (OLIVEIRA; BITTAR, 2010), perpetuando o modelo de manutenção do status quo com a restrição do acesso ao conhecimento às camadas mais abastadas e dominantes.

A Universidade Federal do Recôncavo da Bahia (UFRB) nasce com um projeto diametralmente oposto a essa concepção excludente, elitista e racista. A necessidade de uma universidade na região se fez premente pela importância socioeconômica, política, artística e linguística (NACIF, 2016) do Recôncavo para todo o estado, constituindo uma das regiões mais lucrativas na época canavieira e agregadora de um contingente populacional maior do que o da capital, como registra Nacif (2006).

Todavia, no âmbito do ensino, a Bahia se inseria no limbo do esquecimento da respectiva política pública. No início do século $\mathrm{XX}$, a região nordeste havia se constituído no primeiro conjunto de estados da Federação identificável à precariedade da educação, e detinha as dez posições das maiores taxas do analfabetismo com todos os seus nove estados presentes nesta classificação (FERRARO; KREIDLOW, 2004).

Tanto por suas condições históricas de desenvolvimento quanto pela consolidação de uma precariedade no acesso à educação até os dias hodiernos (FERRARO; KREIDLOW, 2004), construiu-se para a sociedade nordestina um caótico contexto em que seus municípios despontaram, simultaneamente, como os mais fragilizados economicamente e mal desenvolvidos na área educacional (IBGE, 2016).

Com efeito, a região do Recôncavo, economicamente edificada à base da agricultura escravagista e exploratória, produziu na Bahia uma sociedade "desigual e marcada por elevados índices de pobreza e opressão" (NACIF, 2016, p. 23). Foi graças a esse modo cultural e econômico fundador da localidade, bem como a necessidade de aprimoramento agropecuário naquele meio, que o marco educacional na região, em 1850, foi o Imperial Instituto Agrícola da Bahia, mais tarde originando a Escola de Agricultura da Bahia em 1877 e, por fim, a Escola de Agronomia da UFBA (NACIF, 2016). 
Foi somente em 2002, no entanto, que o Reitor da UFBA retomou a discussão da constituição de uma universidade na região, através de debates com parlamentares baianos. Como narra Nacif (2016) essa trajetória:

Em sete de outubro de 2002, em reunião com a bancada de deputados federais e senadores baianos, a Reitoria da UFBA apresentou a proposta de criação da UFRB. No início de 2003, o Conselho Universitário da UFBA, em reunião extraordinária na Escola de Agronomia, pela primeira vez discutiu a proposição do desmembramento para implantar uma segunda universidade federal no Estado da Bahia. O Egrégio Conselho deliberou, naquela ocasião, formar uma comissão especial com o objetivo de elaborar um projeto de criação do que viria a ser a UFRB. Em paralelo, com a finalidade de fortalecer a proposta no contexto territorial, nesse mesmo ano, realizaram-se audiências públicas nos municípios de Amargosa, Cachoeira, Castro Alves, Cruz das Almas, Maragojipe, Mutuípe, Nazaré, Santo Amaro, Santo Antônio de Jesus, São Félix, Terra Nova e Valença. (NACIF, 2016, p. 25)

Dois anos depois do envio do projeto à Presidência da República em 2003, foi aprovada pelo Congresso e posteriormente promulgada a Lei $n .{ }^{\circ} 11.151$, de 29 de julho de 2005, que criou a UFRB (NACIF, 2016).

Desta forma, a inserção da UFRB numa região pobre e oprimida "representou uma grande possibilidade de inclusão social e promoção do desenvolvimento" (REIS, 2013, p. 185), tendo como fundamento a preservação da sua finalidade institucional de promover o papel universitário e atuar como agente de desenvolvimento regional através da oportunização de acesso ao ensino superior.

Consequentemente, exsurge uma relação de câmbio entre comunidade e universidade: enquanto a UFRB influencia a dinâmica socioeconômica mais intensamente nas cidades e microrregiões onde se inserem seus campi, os cursos oferecidos nesses campi tomam as feições locais por meio de um maior número de ingresso de estudantes destas comunidades. É a relação bidirecional citada por Yusuf e Nabeshima (apud CALDARELLI et. al., 2015) onde a universidade se torna um "importante fator de influência para a região em que está inserida" (CALDARELLI et. al., 2015, p. 89), mas "também é influenciada por esta região" (CALDARELLI et. al., 2015, p. 89).

Nesta ordem de ideias, a UFRB se torna a Universidade com um grande número de contingente de discentes negros (UFRB, 2017), correspondendo ao perfil étnicorracial da população do Recôncavo, adquirindo, a partir daí, como "marca definidora de atuação" (NACIF, 2016, p. 27), a promoção do acesso e permanência a um grupo social historicamente alijado do espaço universitário (REIS, 2013). Ingressa na UFRB um público muito diferente daquele habitualmente conhecido pelas universidades, mas um público real para o ambiente em que aquela instituição se instala.

Até a presente data, a UFRB se destaca na execução de políticas afirmativas as quais ratificam sua proposta enquanto instituição promotora da busca da justiça social e do acolhimento das diferenças. A adoção integral da Lei de Cotas pela UFRB foi um ato de reparação de uma gestão historicamente marcada pela manutenção dos privilégios de uma classe dominante. Desde sua criação até 2010 , Nacif relata que os percentuais de discentes afrodescendentes discentes da UFRB eram maiores do que em relação ao conjunto das universidades brasileiras "e, até mesmo, das IFES da região Nordeste" (NACIF, 2016, p. 27), num total percentual de $84,3 \%$. 


\section{Fundamentos da política afirmativa e o novo modelo de ensino dos bacharelados interdisciplinares}

Os Bacharelados Interdisciplinares são resultantes dos modelos americano e europeu de Bolonha, de 1998, que foram recentemente adotados por algumas universidades do Brasil e aqui surgem sob o modelo de Universidade Nova, mediante a proposta de Naomar Monteiro de Almeida Filho (MAZONI; CUSTÓDIO; SAMPAIO et al., 2011).

De acordo com Naomar Monteiro de Almeida Filho, "o regime de ciclos busca formar um novo perfil de estudante-profissional, capaz de aprender continuamente, compreender e analisar criticamente o conhecimento científico, hábil tecnicamente" (ALMEIDA FILHO, 2016, p. 15). O BI tem caráter terminal, podendo o bacharel exercer determinadas funções de nível superior no mercado de trabalho ou prosseguir nos estudos em outros cursos de bacharelados, licenciaturas ou formação profissional, denominadas de terminalidades. (ALMEIDA FILHO, 2016, p. 15). A formação é de três anos e com um terço do curso composto de matérias obrigatórias.

O problema aqui enunciado se verifica pelo fato de a intervenção do Judiciário, em casos como esses, revelar-se uma ingerência extrema na autonomia universitária, cada vez ameaçada pelos projetos de viés neoliberais da política moderna de administração pública. Ademais, o questionamento que vem sendo feito acerca da ilegalidade das cotas universitárias, e o argumento de que as cotas seriam uma vantagem exagerada para quem já obteve o benefício delas, no primeiro ciclo dos cursos de Bl's, vai de encontro ao histórico de lutas pelo fim da discriminação racial, e igualdade de acesso à educação à comunidade negra (SANTOS; ALMEIDA FILHO, 2008), resvalando numa concepção de ação afirmativa mediocrizada, onde, no pensamento dos contestadores das cotas, seria facultado ao estudante negro ingresso, utilizar da política de cotas apenas até o primeiro ciclo; fato que, em verdade, pode redundar numa ineficiência e incompletude do escopo da política afirmativa.

Como consequência disso nos cursos de alto prestígio na UFRB, impugnações e procedimentos judiciais têm afastado pessoas beneficiárias das cotas ao ingresso aos cursos de segundo ciclo. Segundo Boaventura de Souza Santos e Naomar Almeida Filho (2008), a política de cotas deve ser mantida por grande área do BI. A celeuma acera da manutenção da política de reserva de vagas raciais para as terminalidades dos cursos de $\mathrm{BI}$ exsurge a partir da ideia de que uma vez que os estudantes negros ingressassem no curso na modalidade de $\mathrm{BI}$, passariam todos a ficar em pé de igualdade com os demais estudantes, já que "todos os alunos terão acesso aos recursos educacionais e apoio institucional na universidade de acordo com o seu desempenho nos mesmos padrões de ensino" (SANTOS; ALMEIDA FILHO, 2008, p. 229), podendo concluir que eventual progresso nas terminalidades prescindiria de ações afirmativas.

Porém, esta pretensa igualdade não é o que ocorre na prática. O racismo enraizado na academia e na sociedade acarreta o resultado de que os egressos negros dos Bacharelados Interdisciplinares, ainda que invistam em cursos profissionalizantes de segundo ciclo, são excluídos do acesso aos cursos de melhor status, de maneira que as vagas ficariam "reservadas para os mesmos de antes das cotas" (SANTOS; ALMEIDA FILHO, 2008, p. 229). 
Isso decorre porque aqueles egressos negros do BI não viviam, enquanto estudantes, nas mesmas condições financeiras e sociais dos demais estudantes brancos, muitos tendo que dividir o tempo entre estudo e trabalho, com condições de permanência dificultadas em relação aos seus colegas. Explicam Boaventura de Souza Santos e Naomar Almeida Filho:

\begin{abstract}
Mesmo sendo eficiente e inclusiva, a instituição dificilmente compensará o fato de que alguns alunos, vivendo em ambientes sofisticados e estimulantes, podem apenas estudar, contando ainda com recursos e suportes adicionais (por exemplo, contratando cursos complementares), enquanto outros continuarão lidando com problemas econômicos, vivendo precariamente, trabalhando em paralelo ao curso universitário, sem livros, equipamentos e recursos pessoais. (SANTOS; ALMEIDA FILHO, 2008, p. 299)
\end{abstract}

Assim, a possibilidade de cotas nos cursos de segundo ciclo se mostra fundamental para o processo de continuidade da formação do estudante negro, e seu acesso aos cursos profissionalizantes mais elitistas, onde seu perfil racial não é tão presente (SANTOS, 2017).

\title{
3 Judicialização das cotas étnicorraciais
}

Quando se fala de judicialização das cotas étnicorraciais ou litigância na Universidade pública, toma-se aqui o curso de medicina da UFRB como o objeto central destas discussões e narrativas de sofrimentos discriminatórios nesse espaço (SANTOS, 2017), o que torna o tema de raça um ponto nevrálgico no curso mais concorrido da UFRB.

Ademais, enquanto universidade reconhecidamente de perfil negro entre seus discentes e com o título de uma das primeiras instituições de ensino federais a aderir com integralidade o sistema de cotas como determina a legislação (UFRB, 2017), a UFRB possui o desafio de desatar os nós da discriminação racial e fomentar a conciliação entre as contendas desta temática no seio de sua instituição, sob pena de ingressar no paradoxal contexto de se constituir numa instituição de perfil negro onde a luta de raças é permanente e expõe a maioria daquele grupo a constantes ataques acerca do mérito de estarem naquele espaço.

A análise dos dados dos discentes que ingressam nos cursos sob o pálio de comandos judiciais decorrentes de litígios não sobeja dúvidas de que o curso de graduação em medicina é o curso mais litigioso da UFRB. Os dados abaixo mostram que $58 \%$ dos discentes matriculados na UFRB através de decisões judiciais, foram do curso de graduação em Medicina. O percentual revela uma enorme diferença em relação aos demais cursos verificados, conforme tabela a seguir:

Tabela 1 - Cursos com ingressos de matrículas judicializadas

\begin{tabular}{lcc}
\hline Curso & N.o de discentes matriculados & $\%$ \\
\hline Medicina & 39 & 59 \\
Bacharelado Interdisciplinar em Saúde & 4 & 6 \\
Agronomia & 3 & 4,5 \\
Nutrição & 3 & 4,5 \\
Outros & 17 & 26 \\
\hline Total & $\mathbf{6 6}$ & $\mathbf{1 0 0 , 0}$ \\
\hline
\end{tabular}

Fonte: Elaborado pelos autores. 
Diante deste impacto para a universidade em razão do grande número de ingressos mediante processos judiciais, infere-se que há uma situação de litigância ampla como instrumento a fim de que se faça a vontade de determinados pleiteantes às vagas, não através do processo seletivo regular, mas por força de mecanismos extrauniversitários que impõem à gestão da UFRB o ingresso de discentes à revelia de suas normas e processos internos.

Apesar do número de 39 (trinta e nove) estudantes matriculados pela via judicial, o número de processos judiciais movimentados contra a Universidade é bem maior: 57 (cinquenta e sete); revelando que, embora nem todos os litigantes obtenham sucesso no ingresso da Universidade, a maior parte deles consegue afastar o sistema de cotas para acessar o curso de medicina.

Desse grupo de 39 matrículas judicializadas, apenas 2 (duas) são relativas a impugnações aos métodos de aferição fenotípica dos cotistas. As demais 37 são impugnações sobre a validade de aplicação do sistema das cotas no processo seletivo para ingresso no curso de graduação em medicina.

Analisando os argumentos desses 37 processos judiciais que geraram a matrícula de alunos nãocotistas, afastando a política afirmativa prevista em edital na seleção para o curso, foi possível categorizar dois fundamentos idênticos em todos os pedidos iniciais de demandas movidas contra a UFRB.

Primeiro, o argumento de ilegalidade. As teses autorais argumentam que a UFRB não teria o condão de criar norma com preceitos, obrigações e direitos não constantes em lei federal e, em razão disso, o sistema de cotas aplicado para o regime de segundo ciclo seria ilegal por ausência de previsão normativa na Lei $n .{ }^{\circ}$ $12.711 / 12$.

Sabe-se, contudo, que o regime de ciclos se trata de vertente educacional relativamente nova de aplicação nas universidades, resultante dos modelos americano e europeu de Bolonha, de 1998, que foi recentemente adotado por algumas universidades do Brasil, entre elas a UFBA, em 2009. (MAZONI, CUSTÓDIO, SAMPAIO et al, 2011). Pela pouca experiência social com tais modelos educacionais inovadores, a legislação brasileira regulamentadora da política de cotas previu apenas o modelo clássico de ensino, mormente porque a discussão desta lei remonta da década de 90 , muito antes de qualquer aparição brasileira dos BI. Natural, portanto, que a lei de cotas não aborde tal regime.

Tal omissão da lei, todavia, nunca foi fator para que a universidade promovesse direitos, afinal, rememorando a discussão das cotas étnico-raciais no país, foram as universidades, por seus Conselhos Universitários, que fizeram a vanguarda normativa do projeto de cotas, não o Congresso (SILVA, 2006). Assim, o argumento de ilegalidade pelo sistema de cotas aplicado pela UFRB esquece importante momento histórico de autonormação das universidades (FERRAZ, 1999), resultante da autonomia dessas instituições.

Como segundo argumento de contestação, tem-se a violação à isonomia. Argumentam sempre os autores que os egressos dos Bacharelados Interdisciplinar em Saúde estariam em condições de igualdade, não importando a etnia/raça dos discentes. Trata-se de um argumento que ignora as subjetividades dos sujeitos. É com este argumento que as contestações têm vencido. 
As decisões procedentes aos pedidos autorais promovidos pelos discentes litigantes, na qualidade de autores das demandas judiciais possuem como arcabouço judicial, a tese de que manutenção das cotas nos processos seletivos internos para os cursos de progressão linear, sob o fundamento de que a ação afirmativa já haveria privilegiado aos candidatos cotistas, quando no processo seletivo para ingresso no Bl. O discurso da quebra da isonomia, e da crença da igualdade entre os discentes é unívoco nas decisões pesquisadas:

[...] não se pode extrair a possibilidade de, estando todos os alunos já integrando a universidade, possa haver novo estabelecimento de preferências em favor de um ou outro grupo de cidadãos. No particular contexto descrito nos autos entendo que a manutenção daquele mesmo fator de discrímen para seleção interna de um grupo de alunos já contemplado quando do seu ingresso inicial na universidade, não parece legítima. Isso porque, graduados no Bacharelado Interdisciplinar após a integralização de todos os componentes curriculares com êxito, cotistas e não-cotistas igualam-se em condições para disputar o curso de segundo ciclo. Nesse trilhar, a distribuição de vagas conforme estabelece o item "2" do Edital $n^{\circ} 27 / 2017$ permite que os estudantes que concluíram o curso do BIS em pé de igualdade sejam tratados de forma desigual na disputa pelo curso de segundo ciclo, malferindo, de forma manifesta, o princípio da isonomia, e desprestigiando, por outro lado, a aferição do próprio desempenho acadêmico dos alunos. (TRF 1를 Região, Autos de n. 1005433-98.2017.4.01.3300, decisão, grifos do original) Assim considerado, tendo-se que para o ingresso no curso superior, através do Vestibular para - Bacharelado Interdisciplinar, já foi observada a política de cotas e que o acesso ao segundo ciclo de formação se dá com avaliação de conhecimento nos componentes curriculares obrigatórios e optativos do próprio Bacharelado Interdisciplinar, aos quais os candidatos já cursaram em igualdade de condições, entendo que a disposição contida no item 2.1 e seus consectários do Edital n. 013/2018 - que determina a reserva de vaga para grupos sociais específicos (cotas) também para o processo seletivo interno - extrapola os fundamentos da política pública na educação e termina por ferir a isonomia, eis que pretende tratar de forma desigual aqueles que já se encontram em paridade de condições. (TRF 1르 Região, Autos de n.ำ 1004498-24.2018.4.01.3300, decisão).

[...] situação anti-isonômica, ao submeter os egressos do curso de bacharelado interdisciplinar (primeiro ciclo de formação profissional) novamente à política de cotas quando do processo de seleção para o curso de progressão linear (segundo ciclo), o que parece conflitar com a ordem jurídica, ante o nítido favorecimento ao aluno cotista que já se encontra nivelado aos demais, mesmo porque ambos discentes (cotistas e não cotistas) cursaram, em iguais condições, os três anos do Bacharelado Interdisciplinar de Saúde, daí que deve prevalecer a meritocracia ao invés da cotização. (TRF 1르 Região, Autos de n.o 1004790-09.2018.4.01.3300, decisão, grifos do original)

Os fundamentos judiciais, todavia, não se originam de quaisquer dados empíricos, de pesquisas fundadas, aprovadas e aceitas, ou mesmo de dados publicizados, afinal, não há qualquer indicativo dado por tais decisões de que tenham se valido de informações concretas para situar a igualdade entre os discentes. Surgem da simples retórica judicial em acreditar que há na comunidade universitária discente a pretensa igualdade a que aludem. Ou seja, os magistrados se valem do discurso judicial para criar teoricamente um mundo abstrato, validando-o pela força da autoridade do discurso decorrente da posição em que ocupam, imaginando e tomando como verdade o cenário onírico do qual descrevem.

Desta forma, os juízes criam para si, e com efeitos para as partes, uma universidade irreal, à revelia da descrição que a universidade real, ré no processo, apresenta-Ihe de si. A respeito dessa conduta de cultura judicial, critica Warat (1995):

[...] os encarregados de aplicar as leis, os produtores das teorias jurídicas, os professores das escolas de Direito (os construtores das significações jurídicas), forjam uma realidade imaginária (colocada na perspectiva do senso comum) que fazem prevalecer com naturalismo um verdadeiro mundo de faz-de-conta instituído como realidade natural do Direito. (WARAT, 1995, p. 120) 
Nota-se que fica completamente ignorada a condição pessoal dos discentes, antes de se afirmar se estão ou não em pé de igualdade. Desconsidera-se o modo de vida destes, as dificuldades passadas para formar no curso, as condições socioeconômicas, ou mesmo as condições culturais que os impinge sofrimentos diversos entre os próprios colegas, de conteúdo por vezes discriminatório, o qual prejudica a saúde mental dos estudantes e os coloca em evidente posição de desigualdade nos estudos, como já teve oportunidade de avaliar Santos (2017), acerca do curso de medicina da UFRB.

Para os magistrados, o sujeito discente enquanto pessoa, titular de particularidades de uma vida, é alguém que não existe - ou que não merece ser considerado como humano aprendiz. Está substituído no discurso judicial como uma máquina que, posta a aprender conteúdos, uma vez aprovados em determinada grade de disciplinas, são como caixas em que se preenchem frutas numa feira - iguais a todas as outras caixas que contenham a mesma quantidade de frutas. Verdadeiros depósitos humanos de uma educação bancária (FREIRE, 2005).

Esse distanciamento do discurso judicial da condição subjetiva do sujeito revela a total incompreensão sobre as nuances da sociedade. Um operador do direito que ignora dados reais sobre o quanto é difícil para um discente de baixa renda ou vítima de discriminação, ou que acumula emprego, cuidado com familiares e educação, entre outras mais condições de vulnerabilidade estudantil que exigem mais do que o acesso, mas também permanência pela sua condição de sujeito (JESUS, 2007).

Essa conduta judicial, ou expressão de atuar, é denominada por Boaventura (2011) como manifestação da "sociedade longe", que torna o intérprete e aplicador do direito "competente a interpretar o direito e incompetente a interpretar a realidade. Ou seja, conhece bem o direito e sua relação com os autos, mas não conhece a relação dos autos com a sociedade" (SANTOS, 2011, p. 84). Assim, o ator judicial aqui observado é aquele que:

[...] não sabe espremer os processos até que eles destilem a sociedade, as violações de direitos humanos, as pessoas a sofrerem, as vidas injustiçadas. Como interpreta mal a realidade, o magistrado é presa fácil de ideias dominantes (SANTOS, 2011, p. 84).

Tais discursos judiciais, obviamente, não estão sós, tampouco são produzidos de ofício aleatoriamente. É possível concluir que as decisões judiciais proferidas que contém e anulam o desenvolvimento da política afirmativa, sob o argumento reverso da necessidade de manter a igualdade são ferramentas estrategicamente utilizadas pelos grupos étnicorraciais em disputa (SANTOS, 2011) no curso de medicina, os quais, vencidos pela consolidação da política de cotas na universidade, "transfere para os tribunais seus conflitos internos, através de denúncias cruzadas" (SANTOS, 2011, p. 29).

\section{Considerações finais}

Sob o argumento da isonomia, a Justiça viola o direito à autodeterminação de indivíduos, obrigando-os a se encaixarem no perfil desejado que considera correto. A repercussão disso é a diminuição da presença da população negra no curso, pois os negros cotistas são retirados de suas vagas, para cederem lugar aos negros que ocuparam a ampla concorrência. E a ampla concorrência, por sua vez, é cedida para discentes não autodeclarados negros. 
Nenhum estudante negro da lista de classificação foi intimado das decisões judiciais para intervir na busca da defesa de um eventual direito de manter um sistema de cotas do qual é beneficiário. Assim, as decisões que afastam o sistema de cotas se dão à revelia dos candidatos cotistas, os quais são reposicionados na ordem de classificação sem chance de defesa nos autos do processo que enseja tal medida maléfica.

Nota-se que os impactos administrativos das medidas judiciais prejudicam a própria viabilidade da manutenção do curso de medicina, inserido no contexto local, pela razão de não haver suporte para tantos discentes, o que implicaria na necessidade de a UFRB ver reduzida a quantidade de vagas ofertadas por turma de medicina para atender as demandas judiciais. Sob o argumento da escassez orçamentária, o contingente de estudantes em medicina matriculados por força de decisões judiciais pode causar um colapso financeiro na estrutura da UFRB, a qual não seria capaz de comportar despesas com mais docentes e mais turmas a fim de suportar o contingente extranumerário de discentes. Ao lado desse discurso, está ainda a incapacidade administrativa de gerir um número de estudantes não previsto no plano de gestão acadêmico, para o curso de medicina.

Observa-se é que a intervenção judicial, quando não observa os critérios técnicos e políticos da reserva de vagas por cotas étnicorraciais, comete indevida ingerência na Universidade, e ameaça os fins sociais das cotas. Falta conhecimento social, filosófico, antropológico e fundamentação histórica aos/às operadores da lei, ou, quiçá, mais simplesmente, falta-lhes o reconhecimento da necessidade de avaliar socialmente o impacto de suas decisões.

Mas para muito além desse contexto, a discussão das cotas na esfera dos embates judiciais tem demonstrado que a política de cotas ainda não se firmou no entendimento jurídico. Ao contrário disso, sua expansão em novos modelos curriculares de ensino tem sido vista como ameaça e burla a pseudocritérios de igualdade, remontando à antiga discussão das cotas enquanto privilégio, inviabilizando o acesso de jovens negros aos cursos mais elitizados do país e, não por coincidência, com menor representatividade racial. Os tribunais parecem ter se tornado a arena do conflito e o instrumento de assegurar a hegemonia elitista racial sobre cursos de prestígio e poder social. Portanto, ainda há muito que se refletir, debater e garantir no âmbito da ação afirmativa.

\section{Referências}

ALMEIDA FILHO, N. M. O contexto histórico do Bacharelado Interdisciplinar em saúde no Brasil. In: Bacharelado Interdisciplinar em Saúde da UFRB: inovações curriculares, formação integrada e em ciclos. SANTANA, Luciana Alaíde Alves; OLIVEIRA, Roberval Passos de; MEIRELES, Everson. (Orgs.). Cruz das Almas: UFRB, 2016.

ALVES; R.C.D. P.; LIMA; L.C.; SILVA; L.P.; ROCHA, N.C. A Universidade pública brasileira interventiva e inclusiva: um recorte regional no Recôncavo baiano. In: XVI Congresso Internacional FoMerco. Salvador: UFBA, 2017.

CALDARELLI, C. E.; CAMARA, M. R. G.; PERDIGÃO, C. Instituições de Ensino Superior e Desenvolvimento Econômico: o caso das universidades estaduais paranaenses. In: Revista planejamento e políticas públicas, n. 44, jan./jun, Brasília: IPEA, 2015.

CHIZZOTTI, A. Pesquisa em ciências humanas e sociais. 7. ed. São Paulo: Cortez, 2005. 
FERRARO, A. R; KREIDLOW, D. Analfabetismo no Brasil: configuração e gênese das desigualdades regionais In: Educação de jovens e adultos, letramento e formação de professores. Revista Educação \& Realidade. FACED/UFRGS, Porto Alegre: v. 29, n. 2, p. 5- 250, jul./dez. 2004.

FERRAZ, A. C. C. Autonomia universitária na Constituição de 1988. Revista de Direito Administrativo, Rio de Janeiro, v. 215, p. 117-142, jan. 1999.

FREIRE, P. Pedagogia do Oprimido. 43aㅡ ed. Rio de Janeiro: Paz e Terra, 2005.

IBGE. Pesquisa nacional por amostra de domicílios: síntese de indicadores 2015, Coordenação de Trabalho e Rendimento. - Rio de Janeiro: IBGE, 2016. Disponível em:<www.ibge.gov.br>. Acesso em 29 abr. 2017.

JESUS, R. C. D. P. De como torna-se o que se é: Narrativas implicadas sobre a questão étnico-racial, a formação docente e as políticas para equidade. Tese (Doutorado em Educação) - Universidade Federal da Bahia, Programa de Pós Graduação em Educação, Salvador, 2007.

MAZONI, I.; CUSTÓDIO, L.; SAMPAIO, S.M.R. O bacharelado interdisciplinar da Universidade Federal da Bahia: o que dizem os estudantes. In: SAMPAIO, SMR., org. Observatório da vida estudantil: primeiros estudos [online]. Salvador: EDUFBA, 2011, pp. 229-248.

NACIF, P. G.S. Emergência da Universidade Federal do Recôncavo da Bahia: Desafios e percurso na construção de inovações curriculares. In: SANTANA, L.A.A; OLIVEIRA, R.P. (Orgs.). BIS - Bacharelado Interdisciplinar em Saúde: Inovações Curriculares, Formação Interprofissional Integrada e em Ciclos. Cruz das Almas: UFRB, 2016.

OLIVEIRA, J. F. de O.; BITTAR, M.; LEMOS, J. R. Ensino Superior noturno no Brasil: democratização do acesso, da permanência e da qualidade. Revista de Educação Pública, Cuiabá, v. 19, n. 40, p. 201-384, maio/ago. 2010.

OLIVEIRA, C. Negros são menos de $18 \%$ dos médicos e não chegam a $30 \%$ dos professores universitários. Rede Brasil Atual. São Paulo, 03 mai. 2014. Disponível em:

https://www.redebrasilatual.com.br/trabalho/2014/05/negros-no-servico-publico-2996/. Acesso em: 27 abr. 2017.

REIS, D. B. Continuar ou desistir? Reflexões sobre as condições de permanência de estudantes negros na UFRB. In: SANTOS, G.G; SAMPAIO, S.M.R. Observatório da vida estudantil. Universidade, responsabilidade social e juventude. Salvador: EdUFBA, 2013.

SANTOS, B. S.; ALMEIDA FILHO, N. A Universidade no século XXI: para uma universidade nova. Coimbra: Almedina; 2008.

SANTOS, B. S. Para uma revolução democrática da justiça. São Paulo: Cortez, 2011.

SANTOS, D. B. R. Curso de branco: Uma abordagem sobre o acesso e a permanência de estudantes de origem popular nos cursos de saúde da Universidade Federal do Recôncavo da Bahia (UFRB). Revista Contemporânea de Educação, v. 12, n. 23, p. 31-50, jan/abr, 2017.

SEI - Superintendência de Estudos Econômicos e Sociais da Bahia. Estatística dos municípios baianos. Salvador: SEI, v. 13, n. 382, 2010.

SILVA, G. M. D. Ações afirmativas no Brasil e na África do Sul. Tempo soc. [online], v.18, n. 2, p.131-165, 2006.

UFRB. Perfil dos Estudantes de Graduação da UFRB. Cruz das Almas: UFRB, 2017. Disponível em: https://www.ufrb.edu.br/portal/noticias/4800-em-seus-12-anos-ufrb-comemora-maioria-negra-e-pobre-noensino-superior. Acesso em: 29 jul. 2017.

WARAT, L. A. O Direito e sua Linguagem. 2ª Ed. Porto Alegre: Sergio Antônio Frabris Editor, 1995. 